\title{
SUPPRESSION OF SEED GERMINATION AND EARLY SEEDLING GROWTH BY PLANTATION HARVEST RESIDUES
}

\author{
A.W.Schumann, A.W.; Little, K.M. \& Eccles, N.S.
}

The role of forestry plantation residues (leaf and branch) in the suppression of establishment of four weed species (Conyza sumatrensis, Trifolium spp., Echinochloa utilis and Lactica sativa) was investigated. Of the three residue types used, Pinus patula residues were found to have the greatest suppressive effects, followed by Eucalyptus grandis and then Acacia mearnsii. Medium-grade residue was found to be more effective than either the coarse or fine grades, and positioning the +seeds below the mulch resulted in greater suppression than when placed above it. Water extracts from the three residues also resulted in significant suppression of weed establishment, suggesting an allelopathic effect. Finally, suppression of the dicotyledon species was generally greater than suppression of the grass used in this study.

Die potensieel onderdrukkende rol van bosafval (tak- en blaarafval) van plantasies met betrekking tot die vestiging van vier spesies (Conyza sumatrensis, Trifolium spp., Echinoc/oa uti/is en Lactica sativa) is ondersoek. Van die drie tipes bos- afval wat gebruik is, het die van Pinus patula die mees onder- drukkende effek gehad, gevolg deur Eucalyptus grandis en Acacia mearnsii. Bosafval van medium fynheid was meer effek- tief as beide fyn en growwe materiaal, en plasing van die saad onder die deklaag, in plaas van bo-op, het grater onderdrukking veroorsaak. Water-ekstrakte van die drie afvaltipes het vestiging ook betekenisvol onderdruk, wat 'n allelopatiese effek suggereer. Ten slotte, is breeblaarsoorte wat gebruik is in die eksperiment oor die algemeen meer onderdruk as grasse.

Keywords: Mulches, plantation residues, weed suppression

The use of synthetic mulches made from polyester kraft paper and tar wafers, and polypropylene, for silvicultural purposes has generally been shown to enhance plantation tree performance (McDonald \& Fiddler, 1993). This improvement is usually attributed to the mitigating effect of the mulches on adverse temperatures or moisture loss, control of weeds, or the enhancement of soil structure and fertility. In terms of weed control, synthetic mulches have two effects: (1) they reduce the red/far-red light ratio as well as the total quantity of light reaching weed seeds, which may prolong dormancy (Fitter \& Hay, 1987); and (2) they act as a physical barrier to the seedlings or vegetative propagules. The benefits derived from the use of these synthetic mulches are, however, offset by the costs associated with buying, installing and maintaining them.

An alternative to synthetic mulching is the use of plantation harvest residues as mulches (Richardson, 1993). In their 'raw' form, residues hinder site access, and therefore make silvicultural operations such as planting, fertilization, blanking and weed control far more difficult. As a result, residues are usually removed in the cheapest and easiest way (often by burning), with little regard for the impact on site productivity (Norris \& Musto, 1993). However, if the residues are broken down mechanically, they may act as very effective natural mulches. These are fully biodegradable, on site, and depending on the particular site conditions, cheap to produce. In addition to the normal weed-control benefits associated with the use of synthetic mulches, natural mulches may have allelopathic effects on certain weed 
species.

With these considerations in mind, a greenhouse pot experiment was carried out to investigate the suppressive effects of various residue treatments on the establishment of Conyza sumatrensis, Trifolium spp., Lactica sativa (all dicotyledons) and Echinochloa utilis (a grass) planted at a density of 144 seeds/species per 2-1 pot. The experimental design was a $3 \times 3 \times 2$ factorial design with six additional controls and was replicated three times. The pots were arranged in three complete randomized blocks. The first factor was type of residue and comprised the following species: (1) Eucalyptus grandis, (2) Pinus patula, and (3) Acacia mearnsii. The second factor was grade of residue and the three treatments were (1) coarse (150-30 mm), (2) medium (30--7 mm), and (3) fine $(<7 \mathrm{~mm})$, and the final factor was seed sowing position, with the seeds being positioned eier above or below the residue. The additional controls were: (1) no plant residues, (2) water extracts from the three species (Eucalyptus spp., Pinus spp., Acacia mearnsii), and (3) a coarse gravel mulch (with seeds positioned above or below). For the water extracts, each pot received its daily irrigation through a layer of residue equivalent to that in each of the pots with residue. The same residue sample was used for all of the waterings. The measured variates, after 15 days, were above-ground fresh mass of grasses and broadleaves, and percentage cover (assessed by way of video image processing). These were analysed using ANOVA protected leastsignificant differences.

From Figure 1 it is clear that plantation residues could play a very important role in suppression of weeds. Out of the three types of residues used, the greatest suppression of growth was achieved with the pine. This was followed by eucalypt and then wattle residues. These differences were, however, not significant, although the difference between all three types and the no-mulch control was significant. Interestingly, the gravel control seemed to have a greater effect on Echinocloa than any of the three natural residues. The reason for this is not clear. The grade of mulch used also, to some extent, affected the degree of suppression achieved, with the medium residue causing the greatest suppression, followed by the coarse and then the fine (although again this was not statistically significant) (Figure 2). This is possibly due to the fact that the fine residue was too small to offer any real physical resistance to the germinating seedlings, whereas in the coarse residue, there were large spaces between the grains through which the seeds could germinate. This finding has no real practical significance, however, as it is unlikely that the grade of plantation residues could be controlled to this level of accuracy on site. What is important is that all three grades resulted in significantly greater suppression than the no" mulch control. 


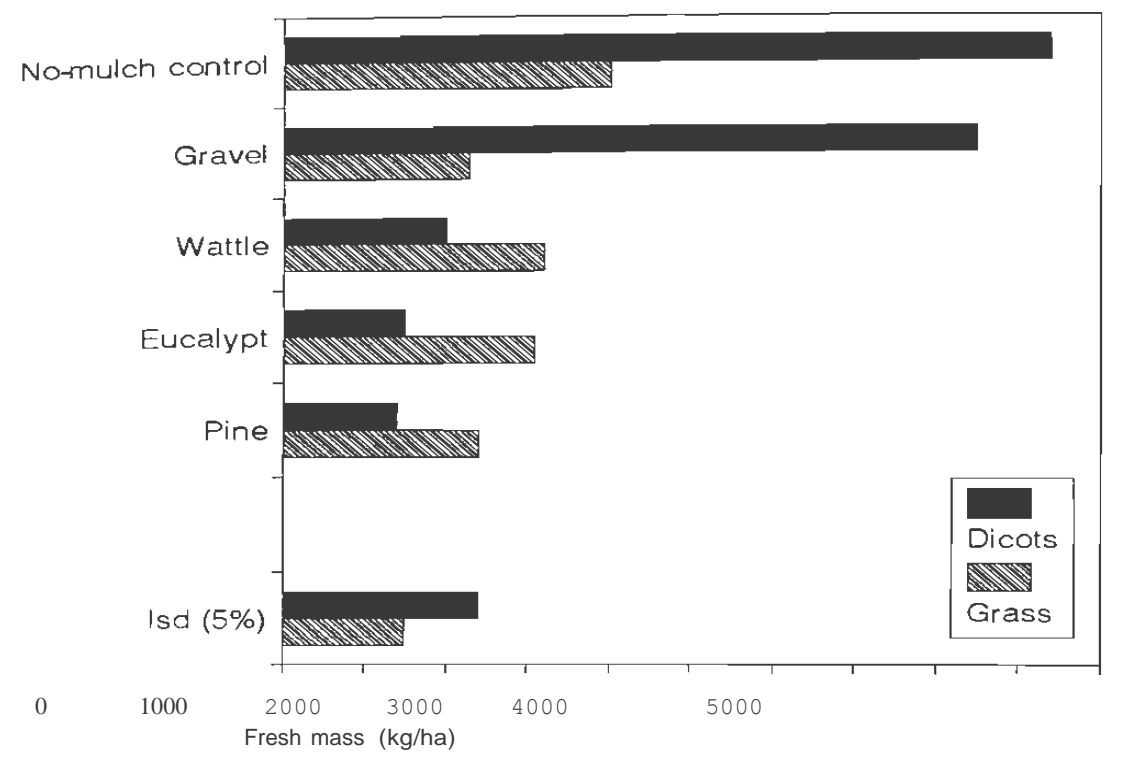

Figure 1 Fresh masses of grass and dicotyledon seedlings as affected by sowing under various types of mulch (both synthetic and natural). Least-significant difference bars (Isd) represent the $5 \%$ level of significance.

The effect of planting position on plant establishment was as would be expected: positioning the seeds below the mulch resulted in greater suppression than positioning them above it (Figure 3). This is again probably due to the physical barrier effect, as well as light-filtering properties of the mulches. Under normal circumstances, shoot growth occurs in a gaseous medium, so shoots are generally not designed to force their way through particularly resistant physical barriers. Roots, on the other hand, usually grow in the soil and are physically adapted for growing through a resistant medium. A residue layer would therefore present a far greater barrier to shoot than to root growth. The suppression observed in the seeds planted above the residue could be the result of three things: allelopathic chemical residues in the soil, drying of the roots as they pass through air pockets in the residue, or the delay in reaching the soil beneath (and therefore the delay in acquiring nutrients). The implication of this is that there is likely to be marked differences in the structure of the weed community between mulched and non-mulched plantation stands, as many of the in situ seeds would be highly sup- pressed, whereas invasive seeds would be less suppressed. 


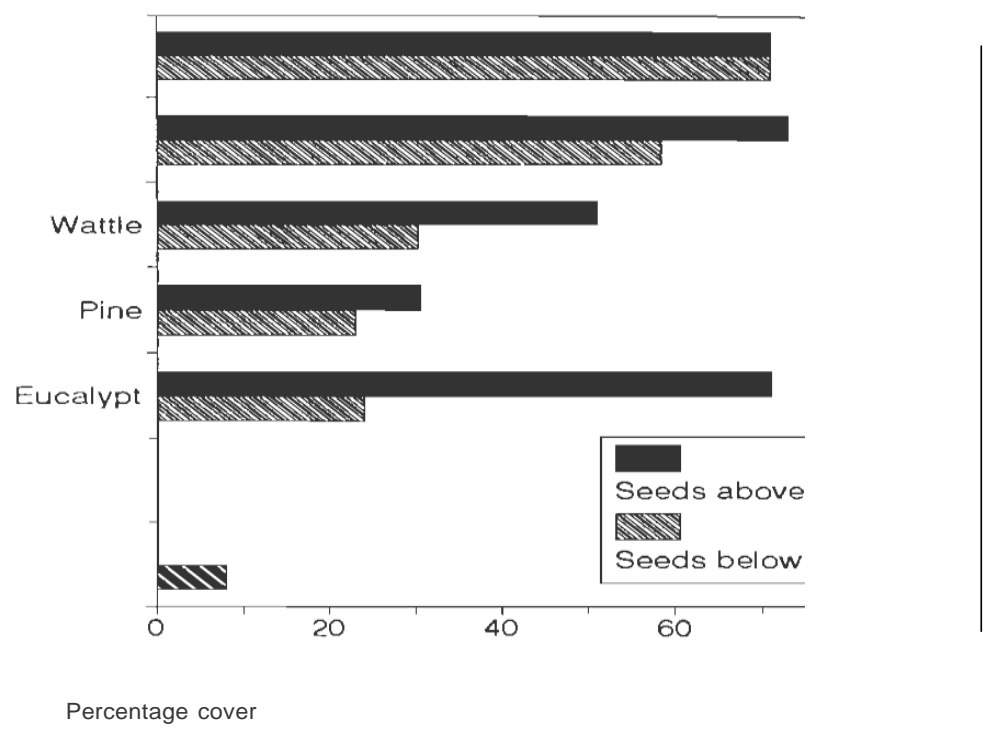

Figure 2 Percentage cover of vegetation in pots as affected by the grade of mulch used. The least-significant difference bar (Isd) is as in Figure 1.

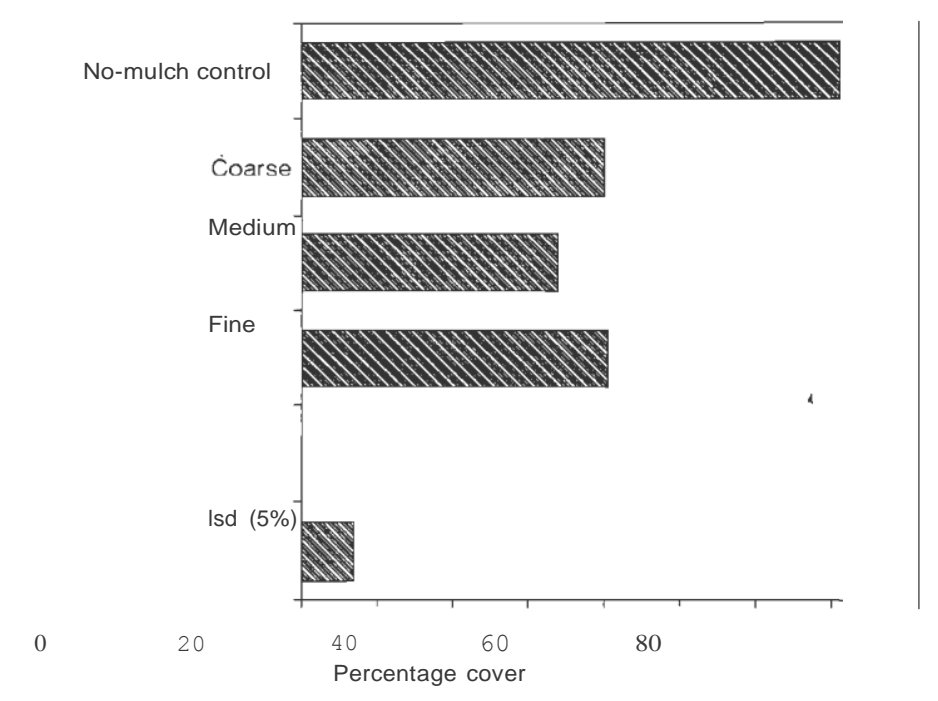


Figure 3 The effects of seed position and residue type on percent- age vegetation cover in the pots. The least-significant difference bar (lsd) is as in Figure 1.

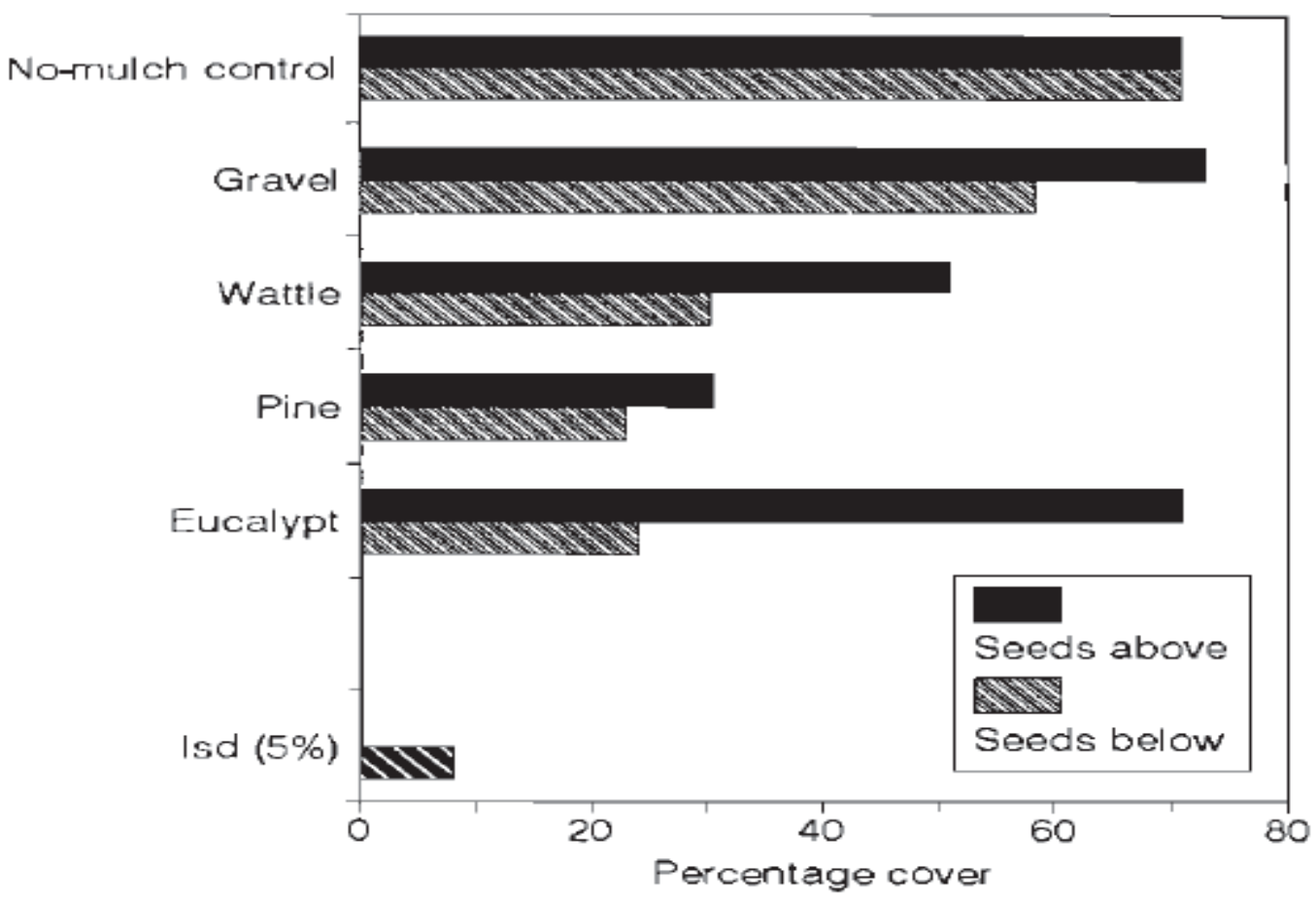

Another interesting observation was that the residues had a far greater suppressive effect on the dicotyledons used in this study than they did on the grass (Figure 1). This enhanced suppression appeared to be the result of the different germination morphology, with the grass being hypogeous. If this differential suppression was found to be a general trend, it would have definite implications for vegetation management in forestry situations. Although the ideal would be to have suppression of both grasses (and other monocotyledons) and dicotyledons, as both appear to have a competitive effect on trees in forestry situations, the suppression of broadleaves is of greater benefit. Grasses can be controlled relatively easily with herbicides, which are reasonably specific (e.g. fluazifop-P-butyl). Specific herbicides for the control of dicotyledons, on the other hand, tend to damage the plantation trees. 


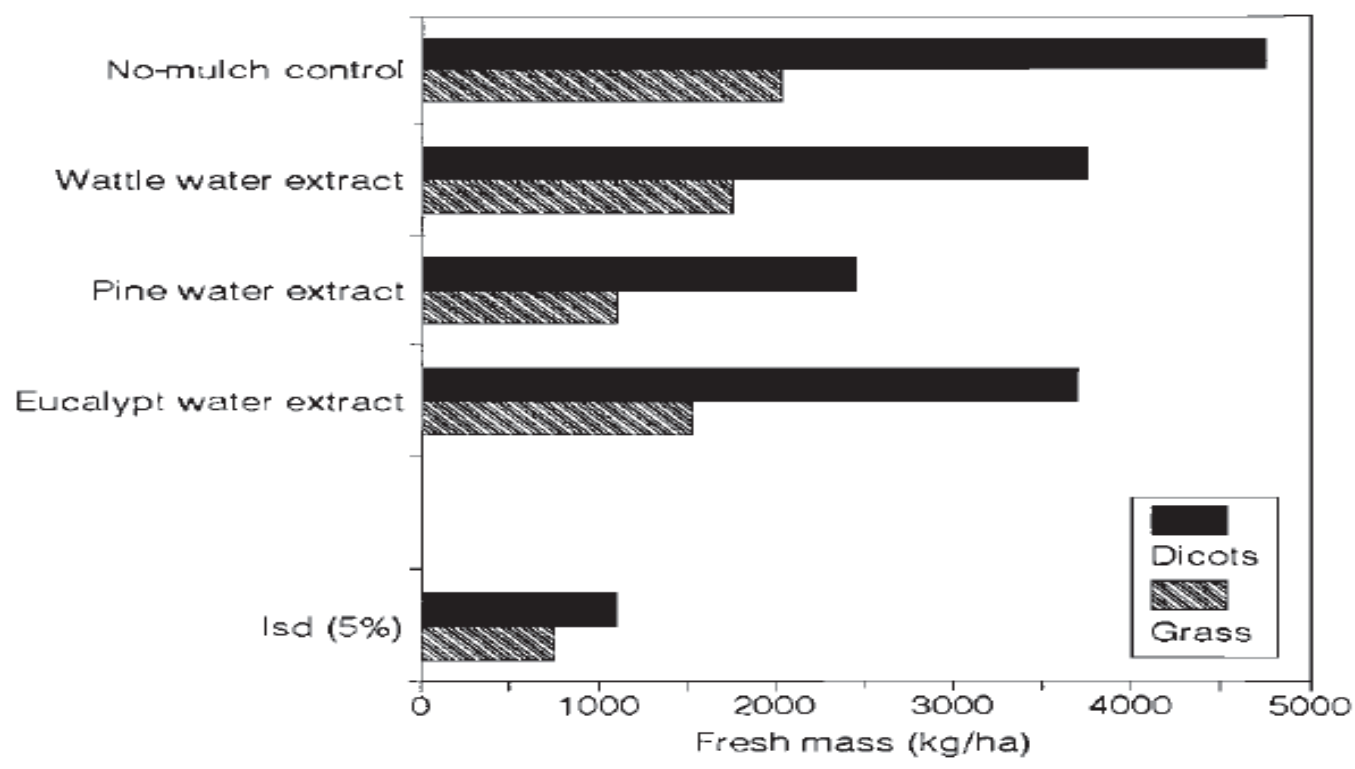

Figure 4 Fresh masses of grass and dicotyledon seedlings as affected by water extracts from the three mulch types (wattle, pine and eucalypt). Least-significant difference bars (Isd) are as in Figure 1 .

Finally, the relative importance of allelopathic effects, as opposed to physical effects, is clear from the suppression brought about by water extracts from the three residue types (Figure 4). The treatment means for all three of the water extracts were lower than the means without extracts. However this response was only statistically significant in the case of the pine (where the allelopathic effect could be the result of acidification). Again the response to water treatments was greater for the dicotyledons, although this was not as pronounced as in the case of the actual mulch treatments. There were also noticeable differences between the different species of extracts used. The pine extract had the greatest allelopathic effect in both the dicotyledons and the grass, followed by the eucalypt, and then the wattle extracts.

To conclude, the results from this trial offer further evidence for the beneficial role of the retention of plantation harvesting residues, in terms of weed control. At present, a number of field trials are under way to confirm whether these findings have any real significance in the field situation.

\section{Acknowledgements}

Thanks to B. du Toit for translating the abstract and to the two anonymous referees for their comments on the draft manuscript. 
Fitter, A.H. \& Hay, R.K.M., 1987. Environmental physiology of plants, 2nd edn. Academic Press, London.

McDonald, P.M. \& Fiddler, G.O., 1993. Feasibility of alternatives to herbicides in young conifer plantations in California. Can. J. For. Res. 23 (10), 2015-2022.

Norris, C.H. \& Musto, J.W., 1993. Plantation residue management. In ICFR Annual Research Report, South Africa.

Richardson, B., 1993. Vegetation management practices in plantation forests of Australia and New Zealand. Can. J. For. Res. 23 (10), 1989-2005. 